\title{
LA ANTROPOLOGÍA DE LA HISTORIA. La memoria y los usos sociales y políticos del pasado. Exploraciones sobre la perpetua danza de la antropología y la historia
}

Ozziel NÁJERA ESPINOSA

Universidad Iberoamericana Ciudad de México

ozzielnajera@gmail.com

Resumen: El presente texto busca establecer los vínculos y limites teóricos que existen entre la antropología y la historia. Para ello se elabora un acercamiento que deja entrever las relaciones existentes entre la antropología y la historia, sus tensiones complementarias, las aportaciones metodológicas de una disciplina a la otra y las diferentes combinaciones que pueden resultar de tan sugestivo ejercicio. A la par se hace un repaso sobre las formas intrínsecas entre una y otra disciplina, la manera en que ambas se enlazan, así como los argumentos que orientan hacia la separación y divorcio de cada materia. Para ello se realiza un recorrido que pone patente cómo es que la especialización disciplinaria de cada ciencia es por un lado necesaria al tratar de entender los fenómenos que se propone estudiar a profundidad; pero, por otro lado, pone de manifiesto sus efectos negativos colaterales, pues puede llegar a dejar de lado visiones, descubrimientos o puntos de vista que enriquecen a cada disciplina.

Abstract: The present text tries to establish the links and theoretical limits that exist between anthropology and history. To this end, an approach is drawn up that reveals the existing relationships between anthropology and history, their complementary tensions, the methodological contributions of one discipline to the other and the different combinations that can result from such a suggestive exercise. At the same time a review is made of the intrinsic forms between the two disciplines, the way in which they are linked together, as well as the arguments that guide towards the separation and divorce of each subject. For this purpose, a journey is made that shows how it is that the disciplinary specialization of each science is on the one hand necessary when trying to understand the phenomena that it intends to study in depth; but, on the other hand, it reveals its collateral negative effects, since it can leave aside visions, discoveries or points of view that enrich each discipline.

Palabras clave: Antropología. Historia. Antropología histórica. Etnohistoria. Remix Anthropology. History. Historical anthropology. Ethnohistory. Remix 


\section{La antropología y la historia: una introducción}

La antropología como disciplina puede abordarse desde diversos causes según el investigador lo desee. Posiblemente sea la más ambiciosa de las Ciencias Sociales, pues no sólo se enfoca en la comprensión de las culturas de todo lugar y tiempo, sino que en sus propósitos puede llegar a abarcar, de manera holística, importantes tópicos como la economía, la política, el parentesco, la tecnología, la religión, el género, el arte, la organización social, el pensamiento, lo simbólico, entre muchos otros (Kaplan \& Manners, 1979: 7).

Las preocupaciones centrales del campo antropológico se asientan en dos temas centrales: a) el cómo funcionan los sistemas culturales, y b) el cómo han llegado a ser lo que son. En este sentido, puede afirmarse que el quehacer antropológico se mueve entre las categorías de la descripción y la explicación, de lo disímil y lo semejante, de la continuidad y el cambio cultural en el tiempo (Ringuelet, Archenti, Attademo, Salva, \& Weingast, 2013: 6).

El ejercicio antropológico exige al investigador -como en toda ciencia- no sólo un corpus suficientemente complejo para poder comenzar a teorizar sobre el tema, sino también el llevar a cabo la discusión de su trabajo hacia diferentes rubros, discusión que será definida tanto por el conflicto que pueda llegar a atravesar tal o cual pueblo, como por las inquietudes subjetivas que filtran el pensamiento del ojo del observador. Inclusive, cabría mencionar los efectos que surte tanto la cultura como el momento histórico por el que atraviesa cada investigador. De allí que podamos encontrarnos con diversas vertientes antropológicas que exigen otros métodos y enfoques.

Desde su surgimiento, las corrientes del pensamiento existentes que se avocan al estudio de la cultura se han centrado irremediablemente en relatar la inmensidad de formas en que viven su cotidianeidad los hombres y las mujeres, a través de la comparación de estructuras que posibilitan el mirar y mirarnos a través de los ojos del otro. Las diferentes concepciones sobre cómo cada cultura enfrenta la variedad de organizaciones mentales humanas; el sueño, la imagen, la familia, el tiempo, el espacio y hasta los mismos procesos de estructuración de los relatos y narrativas que dan vida y sentido a cada cultura.

Es por ello indispensable realizar un acercamiento que nos pueda hacer entrever las profundas relaciones existentes entre la antropología y la historia, sus tensiones complementarias, las aportaciones metodológicas de una disciplina a la otra y las diferentes combinaciones que pueden resultar de tan sugestivo ejercicio. En este sentido, es importante hacer un breve repaso sobre las formas intrínsecas entre una y otra disciplina, los puntos de fuga y tensión, la manera en que ambas se enlazan, así como los argumentos que orientan hacia su separación y divorcio.

Tal trabajo implica no sólo centrarse en la idea de lo que una antropología de la historia puede ocasionar, ya que dicha construcción requiere conjugar y analizar los elementos varios que orbitan alrededor de cada disciplina. Aquí aparece implícito el orden espacio temporal de manera objetiva, así como el pasado, la memoria, lo imaginario, el arte y todos aquellos respaldos historiográficos que sirven para comprender y modificar la percepción que un grupo tiene de sí mismo y de los otros.

Asimismo, es necesario dibujar una línea que sustente y deje ver cómo es que actualmente pueden abordarse de manera antropológica e historiográfica explicaciones socioculturales válidas que coadyuven a comprender la complejidad de los fenómenos actuales a través del uso del recuerdo y la memoria (tanto individual como colectiva), pues, como se pretende demostrar más adelante, los marcos interpretativos mediante los que construimos nuestra realidad presente siempre están mediados por los usos que se le pueden dar al pasado.

Es menester decir que tal práctica no es exclusiva de la antropología, sino que la podemos encontrar también, con profundas raíces, en la sociología o en el estudio de los medios de comunicación, pues, con el gran poder que ostentan actualmente, tienen la enorme facultad de influir en las construcciones del presente, pasado y futuro de una sociedad a través del establecimiento de agendas que determinan qué es lo que se tiene que recordar y qué es lo que se permite que caiga en el olvido.

\section{La antropología y la historia: dicotomías}

En sus inicios, la antropología se fundamentaba como una ciencia de la historia. Sin embargo, los logros positivistas en los rubros de lo físico y lo orgánico orientaron a los antropólogos del siglo XIX a especular sobre las posibles leyes que gobernaban los fenómenos de corte social. Tal convencimiento se enlazó con los ideales ilustradas del siglo XVIII y la concepción de la Historia Universal de la humanidad. Los antropólogos de esos momentos, por muchos vacíos que presentaran en sus planteamientos y con su cientificismo decimonónico, alcanzaron a plantear propuestas que dieron importancia duradera a sus obras.

La antropología se expandiría en los siguientes siglos y los antropólogos de diversas partes del mundo comenzarían casi sistemáticamente a rechazar durante el siglo XX las inútiles pretensiones científicas del 
siglo anterior. El mismo barco en el que estaban trepados los hizo arribar a un puerto en el que se concluía que difícilmente se podrían descubrir los orígenes de las instituciones o sus causas. Particularmente las escuelas norteamericanas llegaron a la afirmación de la inexistencia de leyes históricas, así como a rebatir la imposibilidad de una ciencia de la historia (Harris, 1999: 1).

Las diferencias entre los terrenos de trabajo de la historia y de la antropología con el tiempo se dejaron notar contundentemente. La antropología se centró en el espacio, en el presente del individuo, en el conjunto de relaciones que vincula al grupo social, mientras que la mirada de la historia se avocó al tiempo, la secuencia y la continuidad. El estudio de la alteridad se da en dos dimensiones distintas: la antropología pretende $-\mathrm{O}$ al menos pretendió- trabajar con un grupo social aislado, lejano en relación espacial con el modo de vida occidental, mientras que la historia construyó su otro a través del alejamiento temporal, mediante el cual intentó establecer una distancia suficiente para tener una heterogeneidad cultural (LeviStrauss, 1995: 65).

La antropología, por lo tanto, se concentra en estudiar las instituciones dentro de las cuales los individuos de cada cultura viven su vida cotidiana. Un claro ejemplo lo encontramos en el estudio de las estructuras de parentesco: al conocer dichas estructuras, la observación de los casos particulares pasa a segundo plano hasta reducirse únicamente a ser un ejemplo ilustrativo del funcionamiento de tales instituciones, de esta forma se presupone la existencia de ellas y se califica como irrelevante indagar sus orígenes históricos. Aparece entonces como una antropología de carácter doblemente ahistórica o antihistórica: en primer lugar -señala Korsbaeck- porque, las instituciones que gobiernan la acción individual no tienen un origen o proceso histórico; y, en segundo lugar, debido a que los sujetos que actúan dentro de ellas en realidad no poseen historicidad. La situación es distinta del lado de la historia: la disciplina acepta la presencia de instituciones, mas éstas sólo sirven como estructuras subyacentes de la acción individual sobre las cuales se da el ejercicio de la libertad del sujeto que, de esta forma, se convierte en sujeto histórico (Korsbaek, 2006).

Tal pereciese que por tradición los antropólogos han rehuido y desdeñado las aportaciones de la Historia y de los historiadores. Podemos encontrar claros señalamientos en los que Sir Edward Evan EvansPritchard da testimonio de esta realidad:

"En 1950 tuve ocasión de pronunciar en Oxford la Conferencia en honor de Marett. Entonces dije que consideraba a la antropología más relacionada con ciertas clases de historia que con las ciencias naturales. No diré que hubo allí una. tempestad de protestas, pero, como demuestran las críticas. que se me han dirigido, sí hubo un choque con los prejuicios antihistóricos. La Influencia en este país de Malinowski y de Radcliffe-Brown, ambos extremadamente hostiles a la historia, era todavía dominante. Pero también en otros países ha existido hostilidad o al menos indiferencia ante el método histórico. Durkheim, aunque posiblemente no fuese antihistoricista, sí era ahistoricista y, de cualquier modo, sus estudios sobre desarrollo se hallan más en el terreno de la tipología evolucionista que en el propiamente histórico. Su actitud hacia la historia era ambigua, y creo que no puede ser aceptada. A pesar de las apariencias, en general la antropología en los Estados Unidos, como ha dicho Kroeber ha sido fundamentalmente «de tendencia antehistórica" (Evans-Pritchard, 1961: 1).

Esta ruptura se genera desde la escuela inglesa o funcionalista que tiene como principales exponentes a Bronislaw Malinowski y a Radcliffe-Brown, quienes ponen especial acento en métodos basados en el trabajo de campo ${ }^{1}$. Y pues si hay algo que distingue primordialmente a la antropología, al menos desde Franz Boas y Malinowski, es el inevitable ritual del trabajo de campo intensivo, la llamada observación participante, elevada "a la categoría de deux ex machina" (Llobera, 1975: 10) que forma parte del glamour antropológico, ya que establece las principales bases de la disciplina.

En un afán de entender qué hay detrás del divorcio entre historia y antropología, Evans-Pritchard trata de establecer que la razón fundamental por la que no se han logrado integrar ambos campos se debe a que los antropólogos no han aprendido a tratar de manera sociológica los materiales históricos (Evans-Pritchard, 1961: 5). Para Levi-Strauss, por su parte, el interés del etnólogo, en oposición al del historiador, reposa primordialmente sobre aquello que no está documentado, precisamente porque ese es su objeto de estudio, todo aquello que las sociedades no piensan en fijar sobre piedra o papel. Esta dicotomía Levi-Strauss la resuelve a través del reconocimiento de las facetas inconscientes del investigador y de la vida social. El etnólogo se consagra al análisis de tales elementos, pero sería absurdo suponer que el historiador los ignora, pues éste sólo trata de dar cuenta de los fenómenos sociales a través de los acontecimientos en los cuales

1 Aunque pueden encontrarse textos en los que Malinowski hace buena referencia del uso de la historia y cómo es que ésta puede aportar información valiosa para la etnología, véase por ejemplo la introducción al texto de Ortiz, Fernando, (1983) Contrapunteo cubano del tabaco y el ázucar Ed. Pensamiento cubano /Ciencias Sociales, La Habana Cuba. 
se proyecta la manera en que los individuos de cada periodo han pensado y vivido. La etnología tampoco puede pasar por desapercibidos los grandes procesos históricos en los que se trata de explicar aquello que ha parecido a la humanidad "como la consecuencia de sus propias representaciones y actos". Echar mano de ese complejo aparato de elaboraciones del inconsciente -que algunos como Gilbert Durand llaman imaginario- también es tarea del historiador (Levi-Strauss, 1995: 70-71). La historia no está ligada a los seres humanos ni a ningún objeto específicamente. Su particularidad se encuentra en su indispensable método para inventariar la realidad (Levi-Strauss, 2003: 380).

\section{La antropología y la historia: los remixes}

Alguna vez Henry Ford dijo "No inventé nada nuevo. Simplemente junté los descubrimientos de otros hombres que trabajaron en eso durante siglos" (Craig, 2015), lo que bien nos lleva a plantearnos cómo es que surgen los nuevos inventos tecnológicos, la medicina moderna, las teorías científicas o filosóficas, las narrativas literarias, entre otras. ¿Qué sería de la teoría y acción marxista si no hubiera existido en sus momentos George Hegel? ¿Qué sería de las exploraciones arquetipológicas del mito por Jung sin la teoría psicoanalítica de Freud de sustento? ¿Qué hubiera sido de Comte y los preceptos positivistas que continúan guiando a la academia - y en general a la vida cotidiana- sin la visión de Saint Simón? Para plantearlo de otra forma, cualquier nueva teoría, propuesta metodológica, hipótesis o descubrimiento hecho por el ser humano no tiene una completa originalidad, es un remix: se hizo usando estas tres técnicas: copiar, transformar y combinar (Ferguson, 2012).

Sin duda alguna, gran parte de la cultura como la conocemos hoy en día -y muy seguramente hace 5000 años- es resultado de mezclas de ideas, de relatos, de invenciones que tomaron forma gracias a que la copia, la imitación o los enriquecimientos de ideas no eran sujetos a derechos de autor. Con riesgo de caer en una postura evolucionista, la cultura se desarrolla gracias a que se pueden imitar las ideas de otros y adicionarlas desde la particular perspectiva de cada individuo y cada cultura. No es extraño que encontremos en los relatos judeocristianos restos o reminiscencias de ancestrales narrativas provenientes de mitos mesopotámicos como el poema de Gilgamesh, o venturosas alabanzas al dios Ra entremezclados en el libro de los Salmos. Asimismo, pueden encontrarse en las figuras heroicas de la actualidad presentadas en los comics o en las películas de acción claras citas a obras literarias clásicas, las cuáles a su vez encuentran soporte en los antiguos relatos sagrados de dioses griegos, egipcios o celtas.

También pueden encontrarse diversos contrastes que según el orden de las palabras pueden dar diferentes matices para mezclar el estudio antropológico o histórico, piénsese en la antropología de la historia, la historia de la antropología, antropología histórica, etnohistoria, antropología del pasado, antropología de la memoria, historia cultural, historia antropológica, historia de los conceptos, historia de las ideas, entre otras, apara generar así múltiples combinaciones que presenten el enfoque que más le convenga a cada investigador.

A continuación, se comentará y reflexionará en torno a algunos resultados que han surgido a partir de la combinación o remixes de métodos y visiones en los que intervienen y se entrecruzan la historia y la antropología.

\section{Antropología de la historia}

Occidente no es el único entramado de pueblos y culturas con la capacidad de intentar reproducirse en retrospectiva. No existe una única trayectoria de la humanidad, "cada sociedad tiene su propia vida, su curso, y las sociedades similares son comparables tanto en su historicidad [o modo de desarrollo] como en su estructura" (Durkheim, 1980: 81). Múltiples culturas tienen la necesidad de entender su pasado y para ello recurrir a especialistas, como lo hacemos nosotros. La antropología de la historia se centra en los diversos medios y formas alternativas que podrían ser utilizados para representar el pasado, así como la antropología de la religión intenta ensamblar y comparar las diversas formas en que la religión se estructura en las sociedades del mundo, "la antropología de la historia se ocupa de la epistemología económica de la historia en una sociedad dada" (Stewart, 2012: 3).

Las particulares formas de consciencia histórica que pueda poseer cada sociedad abre de lleno una pregunta antropológica completamente válida como punto de referencia para entender los modos de relación que cada cultura tiene con su percepción del tiempo, de los eventos del pasado, presente y futuro. Recordemos cómo en la Edad Media, bajo la aplastante influencia del cristianismo, las formas de relación con el pasado estaban basadas en la eventual redención que prometía regresar a los momentos mitológicos del "paraíso terrenal y de sus habitantes en los tiempos fabulosos que precedieron a la historia" en un bucle de eterno retorno (Eliade, 1999: 38). Tal premisa implica que diferentes contextos culturales son capaces 
de desplegar diferentes modalidades de acción, conciencia y determinación histórica: sus propias prácticas históricas (Sahlins, 1983: 518).

Si ponemos en contraste -cómo suele hacerlo el método antropológico- el conjunto de sucesos y fechas que se acomodan secuencialmente en el tiempo de la historia de Occidente, contra las sociedades sin historia, puede encontrarse en éstas últimas un principio de atemporalidad, mediante el cual el pasado puede ser activado en el presente mediante el significado, la transmisión de una relación social, una leyenda tribal, el mito, un principio cósmico, un poema, un individuo, la adhesión a un jefe o a un rey, un héroe cultural, una memoria reciente, la imagen o el símbolo, por citar algunas de las complejas formas de relación de otras culturas con el pasado. Las situaciones pretéritas de las sociedades que pueden ser consideradas ahistóricas pueden ser explicadas a través de los relatos fundadores que la conforman, y también en referencia a una serie de narrativas constituidas que componen la realidad. Tales narrativas no tienen que ser meramente mitológicas, pero sí estructuradoras de sentido. La antropología de la historia trata de multiplicar las diferentes concepciones de historia por una diversidad de estructuras que ayuden a comprender la complejidad de cómo los seres humanos se relacionan con la conformación de su pasado.

\section{Antropología histórica}

Existen nociones entremezcladas de los límites de la antropología histórica, algunos que reclaman el nombre en la ausencia de uno mejor para la etnohistoria (Russell \& Berdan, 1998: 5), otros por el contrario, la consideran en un campo muy definido como una antropología de lo que el investigador ya no puede presenciar en vivo, apoyada en sucesos socioculturales pasados de acceso mediante documentos, restos, materiales in situ, en museos, narraciones de vida de cautivos, viajeros, refugiados, misioneros y relatos que subsisten de los actores actuales delas culturas contemporáneas. La antropología histórica se aboca a conocer las sociedades que ya no tienen voz viva, por lo que también requiere de apoyo en la arqueología. Su método combina la intensa búsqueda de archivos y la presencia del investigador en el terreno mismo para juntar datos y contar una historia del pasado y del presente (Dube, Martín, \& Picazo, 2009: 69), en una disposición de la práctica etnográfica, reuniendo consideraciones de las texturas temporales de las formaciones culturales y las transformaciones sociales. La intención de esto -parafraseando a Marshall Sahlins- es que las historias oscuras de remotas islas merezcan un lugar "junto a la autocontemplación del pasado europeo" (1997: 73).

La antropología histórica surge como una respuesta a la ausencia de los sujetos históricos en las etnografías de la primera mitad del S.XX, donde los elementos culturales se mostraban como imperturbables ante los cambios y las mutaciones, las rupturas y las continuidades que dieron forma al pasado y al presente (Dube, Legorburo, \& Muñoz, 2007: 605). Otras posibles connotaciones provienen de los terrenos de la historia cultural. Marc Auge habla sobre la sensibilidad que algunos historiadores durante los años 70 sintieron por analizar la maraña de los social e imprimieron elementos del método antropológico a sus modelos históricos.

En 1975 Jacques Le Goff llama a su seminario "antropología histórica" expresión con la que designa un esfuerzo por llegar, lo mismo que el etnólogo, "al nivel más estable, más inmóvil de las sociedades" (Augé, 1998: 23). Ese intento se inspira también en el programa con el que se denominaba a la "historia de las mentalidades", tal como la pensaba Marc Bloch en los momentos en que recomendaba estudiar la lógica "de los comportamientos colectivos menos voluntarios y menos conscientes" (Augé, 1998: 23).

La antropología histórica como tal sólo ha sido institucionalizada -según Viazzo- en el ambiente académico alemán, y tuvo allí sus inicios como una iniciativa de historiadores ávidos de independizarse de las corrientes del conservadurismo metodológico de la ciencia histórica tradicional alemana, en un medio académico que había sido desamparado por la renovación de Annales y la nueva historia social británica. De hecho, el término se usó en Alemania tan atrás como en 1968, formándose un Instituto de Antropología Histórica en 1973 en Friburgo (Viazzo, 2003: 20-22).

\section{La etnohistoria}

La rápida expansión imperialista del siglo XIX produjo una creciente incorporación de pueblos al orden colonial impuesto. Este proceso vino acompañado de la urgencia de diseñar técnicas de observación y descripción para facilitar el control político y religioso. Para esos momentos tanto el término "etnohistoria" como su pariente, la "etnología", poseían diversas connotaciones. Esta última hacía referencia, inicialmente, al estudio del hombre, pero cuando fue reemplazado por el de "antropología", su denotación se tornó hacia el análisis histórico de la sociedad y las costumbres (Krech, 2000: 213). Para 1900 el consenso sobre su significado se disipó y se comenzó a asociar más con el estudio de la cultura material o con las nacientes antropología social y cultural. 
El término etnohistoria, como lo explica Bernard Cohn (Cohn, 1974: 418), surgió en la década de los 40 del siglo XX con algunos antropólogos, arqueólogos e historiadores norteamericanos que concentraban sus estudios en los aborígenes americanos. En tales investigaciones, se empleaban materiales etnográficos e históricos, para lograr una fusión que Melville Herskovits denominó "método etnohistórico" (Herskovits, 1949: 549).

Marc Auge entiende que el objeto de estudio de la etnohistoria son aquellas sociedades ágrafas cuyo registro del pasado persiste mediante objetos o mitos. Su finalidad es registrar la herencia cultural de pueblos sin manifestación consciente de su propia cultura. Asimismo, se interroga sobre la historia real de las sociedades que estudia y sobre la calidad y los testimonios que recoge de dichas sociedades, por lo que cuestionarse sobre la tradición y transmisión oral, frente a las posibilidades de cotejar y comparar tales testimonios va de la mano de la documentación con los materiales escritos que el investigador pueda recoger (Augé, 1998: 19).

Las fuentes para el etnohistoriador se expanden hasta el significado de mitos, sonidos de tambores o rituales, por lo que también cabe interrogarse sobre las particularidades de cada modalidad de la memoria. El investigador aprende, por ejemplo, a interrogar los silencios, los olvidos o las deformaciones de las genealogías, aprende a apreciar el papel real y el funcionamiento ideológico de un suceso magnificado por la tradición.

La práctica etnohistórica posee fuertes lazos con la antropología histórica al extender su alcance al estudio de las culturas desaparecidas por extinción o aculturación derivada de la conquista o colonización, utilizando fuentes escritas. De esta forma, la etnohistoria establece una variante del método histórico impuesta más por las circunstancias particulares de la obtención de información que por requerimientos internos de un enfoque disciplinario, próximo a la arqueología, cuyo método apela a los restos materiales o a la linguiística histórica, que se apoya de la herencia cultural acumulada en el lenguaje (Santamaría, 1985: 467).

La correspondencia entre historia y antropología que florecía a través de una etnohistoria clásica y tradicional, usualmente limitada a la historia documental de algunas comunidades, particularmente las indígenas, se instituye actualmente de otra forma ya que se ha elaborado una discusión más compleja sobre la temática a raíz de la progresiva colaboración entre ambas disciplinas. Es así como se asoman tendencias que sugieren el reemplazo del término etnohistoria por el de antropología histórica.

\section{La memoria como categoría y los usos sociales y políticos del pasado}

Como puede verse, tanto la antropología como la historia han tratado de estructurar y combinar métodos más complejos en un afán de complementar las carencias que ambas disciplinas pudieran llegar a encontrar cuando se acercan a sus fenómenos de estudio.

Los cambios que las Ciencias Sociales comenzaron a experimentar, en un proceso de autorreflexión -particularmente durante la segunda mitad el siglo XX- orientaron a los historiadores a apoderarse de la historia de la Segunda Guerra Mundial, mientras que los sociólogos y, poco después, los etnólogos comenzaron a enfocar su atención a las comunidades obreras y campesinas en vías de disolución: se recogen entonces testimonios, historias de vida y recuerdos individuales o compartidos del pasado.

La renovación que recibió la historia una vez conformada la Escuela de los Annales -iniciada en los años 20 del siglo pasado- impulsó una generación de historiadores que se apuntalaron de los escritos cincuentistas de Braudel y el entusiasta apoyo que éste daba a las aproximaciones multidisciplinares, así como a una epistemología de los tiempos históricos (Barriera, 2013: 22). Mientras que la antropología voltea hacia las ciudades fundando un campo de estudios centrado en los procesos culturales de la urbe; la psicología permea contundentemente los campos de la sociología, la etnología y la historia, muestra de ello puede verse en los trabajos de Roger Bastide como Le rève, la transe et la folie, Sociologie des maladies mentales o Les Religions africaines au Brésil donde impulsa el estudio de la sociología del sueño, la sociología de las enfermedades mentales, pero con más impacto el estudio de la memoria, el cual abordaba desde métodos tomados desde la etnografía, los planteamiento de Maurice Halbwachs y su teoría de la "memoria colectiva" desarrollada en Les Cadres sociaux de la mémoire (1925), La Topographie légendaire des Évangiles (1942) y La Mémoire collective (1950).

En Francia, son los historiadores, sobre todo Pierre Nora y Jacques Le Goff, (éste último abogaba por la conveniencia de oír e intercambiar enfoques con los etnólogos), quienes a mediados de la década de 1970 se preocupan por promover la noción de "memoria" en las ciencias sociales. La "memoria" remite así a todas las formas de la presencia del pasado que aseguran la identidad de los grupos sociales y especialmente de la nación. No es historia, por lo tanto, en cuanto ésta tiende a la inteligibilidad del pasado, y tampoco es, propiamente hablando, recuerdo: es "economía general y administración del pasado en el presente" (Lavabre, 2007). 
El uso más común de la noción de memoria colectiva evoca a la memoria compartida de un suceso del pasado vivido en común por una colectividad, extensa o delimitada, por lo que puede encontrarse, por ejemplo, en una nación, aldea o familia. Pero comprende, asimismo, la historia o lo que se denomina "memoria histórica", en cuanto garante de la permanencia de las grandes mitologías colectivas:

El interés prestado a los testimonios, los relatos de vida, las autobiografías de los actores de la historia, célebres o anónimos, poderosos o dominados, que, en todos los casos, suponemos representativos de sus grupos de pertenencia, corresponde al primer uso, vale decir la memoria compartida de un acontecimiento; se funda en la ilusión de que el pasado puede ser vertido en presente (Lavabre, 2007).

Otro uso compartido de la memoria colectiva es su carácter de "memoria nacional", por ejemplo, el conocimiento compartido de las conmemoraciones de las hazañas de los héroes de la historia nacional da cada pueblo, representada en los libros de texto o en los monumentos históricos u otros lugares con significado. Básicamente la definición se sustenta no en el recuerdo aprehendido mediante del testimonio, sino en la elemental diferencia de la historia y la memoria. Así, la "memoria colectiva" sería entonces

un conjunto de manifestaciones que no sólo revelan, hace ver, leer o pensar la presencia del pasado, sino que tienen la función de estructurar la identidad del grupo o de la nación, y por ende, de definirlos en tanto tales y distinguirlos de otras entidades equiparables. es tan pronto evocación, recuerdo de un suceso vivido, narración, testimonio o relato histórico, como elección del pasado, interpretaciones y hasta instrumentaciones de éste, conmemoración, monumento, e incluso huella de la historia y peso del pasado (Rousso, 1991).

El uso del social y político del pasado está estrechamente vinculado con la memoria. La expresión trata de dar cuenta de cómo diversos actores sociales apelan al pasado, y a la historiografía, para obtener evidencia y argumentos que apoyen las agendas de acción en el presente. Es invariable el factor histórico que pasa inadvertido a fuerza de su presencia. La historia está ampliamente relacionada con la memoria, a tal grado que en ocasiones se enmarañan. Las dos se fundamentan en el pasado y ambas conciben el pasado en el presente; contienen una dimensión individual y a su vez un sentido colectivo.

Difícilmente los sectores hegemónicos escapan de hacer uso de esta antigua estrategia en la que se seleccionan los episodios, los símbolos y las narrativas del pasado que les ayudan a legitimar en el tiempo su razón de ser. Para tal labor se recurre a elementos que confeccionaran un discurso que se fundamente en imágenes generadoras de emociones y escenas que constantemente son citadas para reforzar los sentimientos nacionalistas, la identidad, las ideas o hasta los impulsos consumistas. No resulta extraño encontrar las constantes citas en los discursos políticos - lo cual se ha convertido en un ejercicio muy bien pagado- sobre los valores por los que se ha peleado en el pasado y la necesidad de perpetuarlos (López Bernal, 2011: 35).

El uso del pasado se puede imponer como una forma de olvido al establecer narrativas dominantes, extraídas directamente de la historia y la memoria, pasadas por el filtro de cualquier ideología o facción política para presentarse como un patrimonio turístico, en un museo, rituales públicos, libros de texto y demás artefactos de la cultura de masas con efectos sorprendentes (Dowd Hall, 2005: 1233).

\section{A manera de cierre}

Antropología e historia son disciplinas que actualmente comparten no sólo métodos y miradas, sino que son complementarias para acceder tanto al conocimiento de los seres humanos inmersos en su cultura, como su posición en el tiempo. El espacio de la antropología es inevitablemente histórico y está cargado de sentido por las interacciones humanas y sus procesos de simbolización que, organizados en complejos sistemas, dan orden a la vida social. Tal estructuración simbólica de la vida y lo social es inevitablemente anterior a las herramientas y procesos que sirven para interpretarla, por lo que se erige, en ocasiones, como una barrera que se interpone ante los acercamientos de carácter histórico.

Si bien en algún momento ambas disciplinas experimentaron un distanciamiento, tal sirvió para llevar a cabo procesos científicos de autorreflexión como disciplinas aparentemente independientes. Su reconciliación se orientó hacia una búsqueda de explicaciones en torno de los fenómenos sociales y las crisis que encararon después de los sucesos postcoloniales de la Segunda Guerra Mundial. El reencuentro de ambas perspectivas sociales generó frutos que aún hoy en día no terminan por configurarse del todo, pero también logró consolidar enfoques consistentes como el de la etnohistoria, la historia cultural o el surgimiento de los estudios sobre la memoria colectiva.

Valdría la pena continuar este interesante ejercicio y buscar respuestas en otras construcciones teóricas como la historia antropológica o la historia de la antropología, la historia cultural, la historia de las mentalidades y de los conceptos o sus derivaciones en otros campos como la psicología, el arte, la filosofía, la hermenéutica, los estudios culturales -que encontraron profundos ecos en Reino Unido-, así como las perspectivas de estudio del imaginario que se generaron en Francia tras los grandes cuestionamientos que se hacían dentro de las Ciencias Sociales durante la segunda mitad del siglo XX. 
Los remixes culturales y científicos son el tren en el que la humanidad avanza hacia la construcción del conocimiento, de la búsqueda y elaboración del sentido que la sociedad Occidental ha perdido. El recorrido realizado a lo largo de este escrito da cuenta de cómo es que la especialización disciplinaria de la ciencia es por un lado necesaria al tratar de entender los fenómenos que se propone estudiar a profundidad; pero, por otro lado, pone de manifiesto los efectos negativos colaterales, pues puede llegar a dejar de lado visiones, descubrimientos o puntos de vista que enriquecen a cada disciplina. La necesidad de la multidisciplina se hace patente y necesaria un mundo en el que el conocimiento y la información crecen exponencialmente. El desarrollo científico requiere precisamente de perspectivas que se complementen a través de la visión crítica y la cooperación entre las diversas áreas de estudio, tanto aquéllas que se han consolidado por su rigor, como aquéllas más recientes que buscan y exploran otros modos de hacer ciencia.

\section{Bibliografía}

Augé, M. (1998). Hacia una antropología de los mundos contemporáneos. Barcelona, Cataluña, España: Gedisa.

Barriera, D. G. (2013). La antropologización de la Historia Las edades medias de Jacques Le Goff (de Mercaderes y banqueros a La bolsa y la vida). Rosario, Argentina: Prohistoria.

Cohn, B. S. (1974). "Etnohistoria”. En D. L. Sills, \& V. C. Tomás, Enciclopedia de las ciencias sociales (Vol. 5). Madrid, España: Aguilar.

Craig, C. (2015). [Detroit techno]: Musician Snapshots (Series of The Music You Should Hear ed., Vol. 1). Detroid, EUA: Stone Blue Editors SBE Media.

Dowd Hall, J. (2005). The Long Civil Rights Movement and the Political Uses of the Past. The Journal of American History, 91 (4), 1233-1263.

Dube, S., Legorburo, Y., \& Muñoz, A. (2007). Llegadas y salidas: la antropología histórica . Estudios de Asia y Africa , 42 (3), 595-645.

Dube, S., Martín: A., \& Picazo, M. E. (2009). Patrones del Pasado. Un Ensayo Sobre Historia Crítica y Antropología Histórica. Estudios de Asia y Africa , 44 (2), 367-381.

Durkheim, É. (1980). Contributions to L'Année Sociologique. NY, EUA: The free press.

Eliade, M. (1999). Mitos, sueños y misterios. Barcelona, Cataluña, España: Kairós.

Evans-Pritchard, E. E. (1961). Anthropology and History. Manchester, RU: Manchester University Press.

Ferguson, K. (15 de 02 de 2012). Everything is a Remix . Recuperado el 2016 de 06 de 18, de Everything is a Remix The sit about ongoing video series: http://everythingisaremix.info/blog

Harris, M. (1999). El desarrollo de la teoría antropológica. Coyoacán, D.F., México: siglo XXI.

Herskovits, M. J. (1949). Man and His Works: the Science of Cultural Anthropology. New York, EUA: Alfred A. Knopf,.

Kaplan, D., \& Manners, R. (1979). Introducción crítica a la teoría antropológica. México: Nueva Imagen.

Korsbaek, L. (2006). La antropología y la historia: la historia de las mentalidades y la antropología en la actualidad. DF, México: Red Ciencia Ergo Sum ProQuest ebrary.

Krech, S. (2000). Etnohistoria. En T. Barfield, Diccionario de antropología (págs. 213-216). CDMX, México: Siglo XXI.

Lavabre, M.-C. (2007). "Maurice Halbwachs y la sociología de la memoria”,. En A. Pérotin-Dumon, Historizar el pasado vivo en América Latina. Colombia: Universidad Alberto Hurtado .

Levi-Strauss, C. (1995). Antropología estructural. Barcelona, Catañuña, España: Paidós.

Levi-Strauss, C. (2003). El pensamiento salvaje. DF, México: FCE.

Llobera, J. R. (1975). La antropología como ciencia, textos compilados y prologados por J. R. Llobera. Barcelona, España: Anagrama.

López Bernal, C. G. (2011). Mármoles, clarines y bronces. Fiestas cívico-religiosas en El Salvador, siglos XIX y XX. San Salvador, El Salvador: Editorial Universidad Don Bosco- SECULTURA.

Ringuelet, R., Archenti, A., Attademo, S., Salva, M. C., \& Weingast, D. (2013). El campo de la antropología. En R. Ringuelet, Temas y problemas en Antropología Social (págs. 5-40). La plata, Argentina: Universidad Nacional de La Plata.

Rousso, H. (1991). Pour une histoire de la mémoire collective: l'après Vichy. En P. y. Peschansky, Histoire politique et sciences sociales. Paris, Francia: Complexe. 
Russell, B., \& Berdan, F. F. (1998). The Emperor's Mirror: Understanding Cultures Through Primary Sources. Arizona, EUA: Tucson: University of Arizona Press.

Sahlins, M. (1997). Islas de historia La muerte del capitán Cook. Metáfora, antropología e historia. Barcelona, Cataluña, España: Gedisa.

Sahlins, M. (1983). Other Times, Other Customs: The Anthropology of History. American Anthropologist , 85 (3), 517-544.

Santamaría, D. J. (1985). La historia, la etnohistoria y una sugerencia de los antropólogos . Desarrollo Económico , 25 (99), 465-472 Published by: I.

Stewart, C. (2012). Dreaming and historical consciousness in Island Greece. Harvard, EUA: Harvard University press.

Viazzo: P. (2003). Introducción a la Antropología Histórica. (E. d. Curatola, Ed., \& T. d. Fernández, Trad.) LimaPerú: ontificia Universidad Católica del Perú-Instituto Italiano de Cultura. 